\title{
Buried paleo-channels on the New Jersey continental margin: channel porosity structures from electromagnetic surveying
}

\author{
Rob L. Evans ${ }^{\text {a,* }}$, L.K. Law ${ }^{\text {b }}$, B. St. Louis ${ }^{\text {c }}$, S. Cheesman ${ }^{\mathrm{d}}$ \\ ${ }^{a}$ Department of Geology and Geophysics, Woods Hole Oceanographic Institution, Clark 240, Woods Hole, MA 02543-1541, USA \\ ${ }^{\mathrm{b}}$ Pacific Geoscience Centre, North Saanich, BC V8L 4B2, Canada \\ ${ }^{\mathrm{c}}$ Geological Survey of Canada, Geophysics Division, Ottawa, Ont., Canada K1A OY3 \\ ${ }^{\mathrm{d} C u s t o m}$ Geophysical Software, Toronto, Ont., Canada
}

Received 22 April 1999; accepted 31 May 2000

\begin{abstract}
We report on a marine electromagnetic (EM) survey across two portions of the New Jersey continental margin that have been previously shown to contain buried paleo-channels. The EM method used provides bulk porosity estimates to depths of around $20 \mathrm{~m}$ below the seafloor and is thus able to place porosity constraints on the nature of the channel infill and the contrast in physical properties across the channel boundaries. Our data show that a key condition for the channels to have an electrical signature is that they incise an underlying regional unconformity, $\mathbf{R}$, thought to represent a subaerially eroded surface, exposed during the late Wisconsinan glaciation. Channels that cut $\mathbf{R}$ are seen through increases in apparent porosity. Another seismically imaged channel sequence, which lies within the outer-shelf sediment wedge sequence above $\mathbf{R}$, does not have an electrical signature, indicating that the sediments above and below the channel boundaries have similar physical properties. (C) 2000 Elsevier Science B.V. All rights reserved.
\end{abstract}

Keywords: Electromagnetic; Electrical resistivity; Porosity; Continental shelf; Shelf channels

\section{Introduction}

It has become well understood that sedimentary input onto the New Jersey margin has been limited since the last major period of de-glaciation (Emery and Uchupi, 1984; Milliman et al., 1990). In addition, the sequence of exposure and burial associated with glacial activity has resulted in complex patterns of sedimentary structures both with depth and laterally across the margin. Much of the surface morphology reflects a substantial amount of reworking by ocean currents, but also contains long wavelength sand ridge

\footnotetext{
* Corresponding author. Fax: +1-508-457-2023.

E-mail address: evans@hades.whoi.edu (R.L. Evans).
}

structures that were probably formed in a nearshore environment. The present day shelf break here is between 100 and $150 \mathrm{~m}$ water depth, and across the shelf several paleo-shorelines have been mapped.

An unconformity found across much of the shelf is seen as a bright seismic reflector (named $\mathbf{R}$ ) and represents a period when the shelf may have been subaerially exposed (Milliman et al., 1990). Regional Huntec surveying shows substantial variation in sediment thickness on top of $\mathbf{R}$. Two prominent regions of post-R deposition are the mid- and outer-shelf sediment wedges described by Milliman et al. (1990). These wedges of sediment lie ontop of $\mathbf{R}$ and have thicknesses of up to $50 \mathrm{~m}$ on the outermost shelf and in excess of $15 \mathrm{~m}$ in mid-shelf. The two wedges are 
separated by a region where either $\mathbf{R}$ outcrops at the seafloor or is covered by at most a veneer of sands. The mid-shelf wedge lies between 40 and $60 \mathrm{~m}$ water depth. The wedge itself is divided into two depocenters separated by the Hudson divide. The outer-shelf wedge lies in water depths between 65 and $100 \mathrm{~m}$ at its southern end, and trends northeast, increasing in depth as it approaches and overlies the Hudson apron. Milliman et al. (1990) suggest a nearshore deltaic setting for the deposition for these sediments. The substantial thickness of the wedge, in places $50 \mathrm{~m}$ thick, further suggests a rapid deposition.

High resolution and well-navigated seismic surveys have documented some of the morphological complexity of the sediment wedges in terms of a series of buried paleo-channels found within the outer-shelf wedge and at its landward boundary, as $\mathbf{R}$ shoals to within a few metres of the seafloor (Davies et al., 1992; Austin et al., 1996; Davies and Austin, 1997). Both seismic surveys were able to map several prominent seismic reflectors that act as markers for understanding the shelf evolution in relation to glacial events. A widespread, but less regular reflector, dubbed channels, defines the base of most of the buried paleo-channels, although some also incise $\mathbf{R}$. The internal structure of the channels is one key to understanding under what conditions the channels were formed and subsequently infilled, and therefore provides clues to the recent depositional history of the shelf.

Coring, carried out in conjunction with the seismic surveying, has further provided lithological sections through one of the channels. Foraminifers identified within the cores place constraints on the water depths in which the sediments were deposited and indicate a range of shelf environments that each region has witnessed since the channels were carved (Lagoe et al., 1997; Buck et al., 1999). Channel fill material collected on the flanks of an $\mathbf{R}$-incising channel, and dated at $12 \mathrm{ka}$, shows fluctuations in lithology and biostratigraphy indicating a variety of water depths oscillating between marginal-marine and mid-shelf settings.

The formation age of $\mathbf{R}$ is disputed. Carbon dating of cores that sample sediments both within the wedge and below the reflector $\mathbf{R}$, place a date for the formation of the reflector as around $20 \mathrm{ka}$, but possibly as old as $40 \mathrm{ka}$ (Knebel and Spiker, 1977; Lagoe et al.,
1997; Buck et al., 1999), although the older of these ages probably reflects sediments from below $\mathrm{R}$ that have been re-worked to a position above the reflector. Duncan et al. (2000) argue that the spatial characteristics of $\mathbf{R}$ define it as being formed when sealevel was around $75 \mathrm{~m}$ below present depths, and that this would place a formation age at around $30 \mathrm{ka}$. Others prefer a younger date for the formation of $\mathbf{R}$ (Milliman et al., 1990; Davies et al., 1992; Uchupi et al., 2000). Uchupi et al. (2000) argue that the entire $\mathbf{R}$ surface was subaerially eroded, in which case the outer shelf could not have been eroded much before the late Wisconsin, 18.5-22 ka, when the maximum sealevel low-stand occurred placing sealevel about $120 \mathrm{~m}$ below its present level. While Uchupi et al. (2000) argue that this was when $\mathbf{R}$ was formed, Duncan et al. (2000) use this time period for the formation of subaerial incision of the series of dendritic channels.

Given the dispute over the age of $\mathbf{R}$, it is not surprising that there are also competing models for the emplacement of the two sediment wedges. Following Milliman et al. (1990), Uchupi et al. (2000) suggest and document evidence that both wedges of sediment were derived from the catastrophic breaching of glacial lakes. Duncan et al. (2000) argue against a catastrophic provenance for the sediment, but instead argue that the wedges constitute rapidly emplaced subaqueous deltas associated with the Hudson River system.

\section{Methodology}

We report on an electromagnetic survey of the New Jersey margin to the south of the Hudson Canyon and Apron, covering the same two areas that had been the focus of previous 3D Huntec coverage (Davies and Austin, 1997; Davies et al., 1992; Austin et al., 1996).

Seafloor EM methods use the physics of induction to provide an increased sensitivity to changes in seafloor properties over conventional resistivity techniques. The EM survey used a towed frequency domain system operated by the Geological Survey of Canada (Cheesman et al., 1993; Evans et al., 1999). The system consists of a transmitter, which generates time varying magnetic fields over a range of frequencies, and three receivers, tuned to measure these magnetic fields, which are towed at fixed 


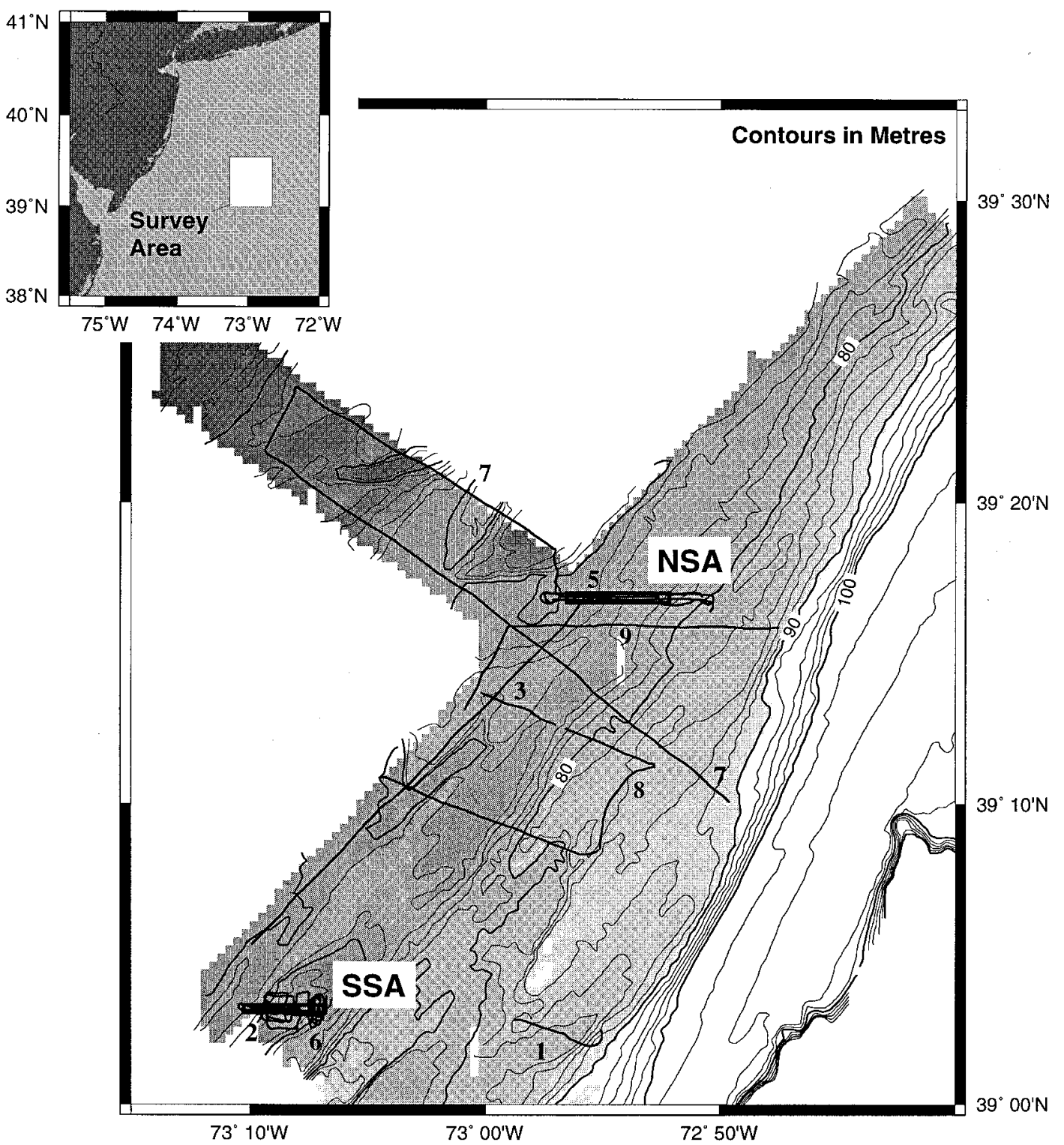

Fig. 1. A bathymetric map of the survey region (Mayer et al., 1996; Goff et al., 1999) showing all the lines completed during the cruise. The two regions of dense coverage are the areas referred to as the NSA and SSA in the text. These areas had been the focus of previous 3D highresolution seismic surveys with the Huntec system (Davies et al., 1992; Davies and Austin, 1997; Austin et al., 1996). Line numbers referred to in the text are denoted on the map.

distances of 4, 13 and $40 \mathrm{~m}$ behind the transmitter. At a given frequency, the magnetic fields decay in strength away from the transmitter in a manner that depends on the conductivity of the seafloor, and decay more rapidly in more conductive media. This means that if frequencies are chosen appropriately, a measured signal will have primary sensitivity to changes in sub-seafloor properties, and will not be affected greatly by the overlying conductive seawater. Each receiver is tuned to record three frequencies and the information in each consists of a magnetic field amplitude and phase. Thus, a set of raw measurements 


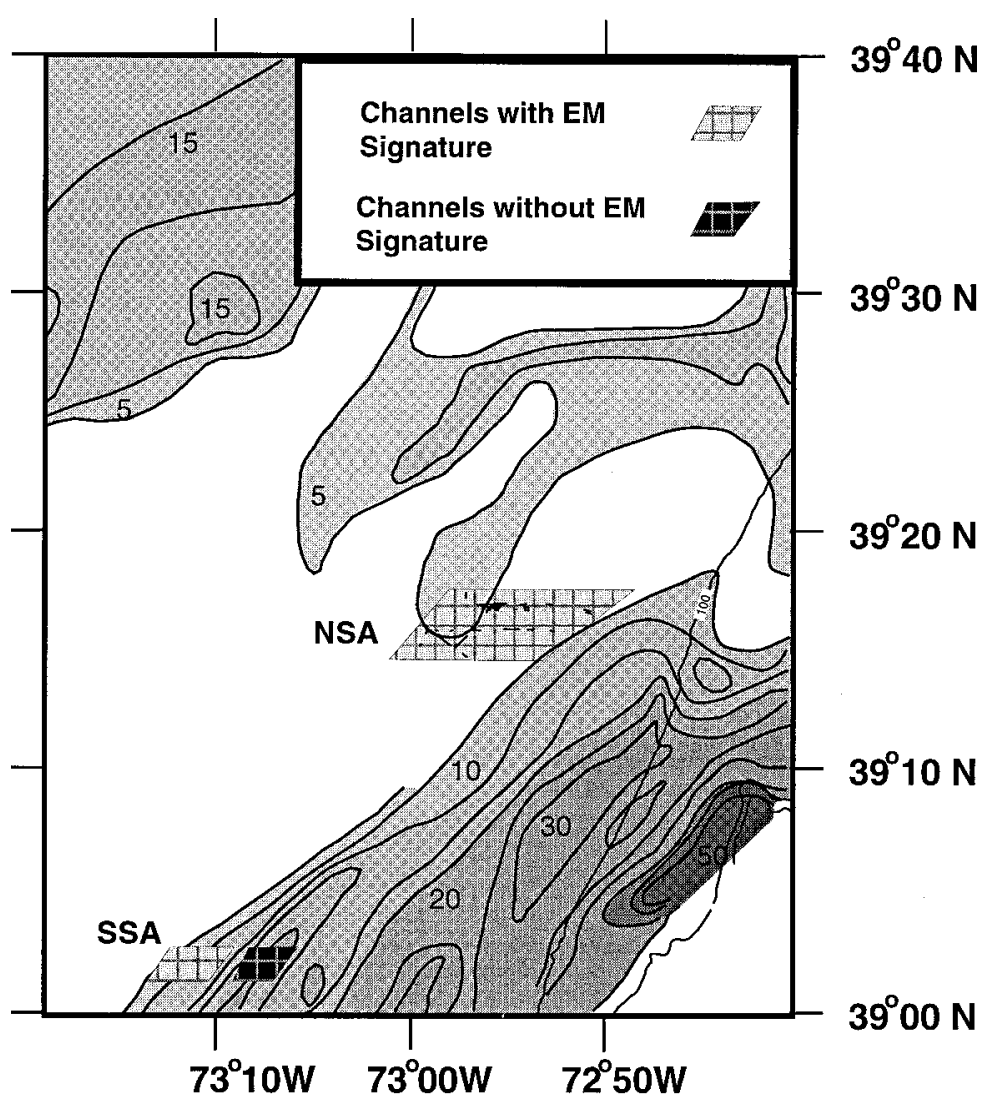

Fig. 2. An isopach map of late Quaternary sediment deposited as an outer- and mid-shelf wedge on top of the regional unconformity $\mathbf{R}$ (from Milliman et al. 1990). Also shown are regions where the EM system finds measurable responses from buried paleo-channels, as well as a region at the eastern end of the SSA where seismic reflection shows a coherent meandering channel system which has no discernible EM signature. Contours of sediment thickness are shown at $5 \mathrm{~m}$ intervals.

consists of nine amplitude and phase values at each transmission station along a tow-line. The system is dragged along the bottom at speeds of 1-2 knots and makes a set of reading every $10 \mathrm{~m}$ or so along track. It is possible to take a set of amplitude and phase values and invert all of them for a resistivity-depth profile. In practice, a more efficient and straightforward means of looking at the data is to take the three amplitudes and phases recorded by each receiver and find the best-fitting apparent resistivity for each: an apparent resistivity is the resistivity of the uniform seafloor half-space that would best reproduce the observed response. Since all the recorded values have associated errors, and the seafloor is not a half-space, this is only an approximation, but the apparent resis- tivity does provide a reasonable average resistivity over the depth of sensitivity of each receiver. In general, a receiver that is a distance $L$ away from the transmitter will be sensitive to structure over a depth range up to about $0.5 \mathrm{~L}$ below the seafloor. By having receivers spaced 4,13 and $40 \mathrm{~m}$ behind the transmitter, we are able to obtain information over the top $20 \mathrm{~m}$ of seafloor. The apparent resistivity of the $4 \mathrm{~m}$ receiver provides average structural information about the uppermost $2 \mathrm{~m}$ of seafloor, the $13 \mathrm{~m}$ average over about $6-7 \mathrm{~m}$ while the $40 \mathrm{~m}$ receiver averages over $20 \mathrm{~m}$ of seafloor.

Apparent resistivity values are converted into apparent porosities using Archie's law (Archie, 1942), an empirical relationship relating porosity to 

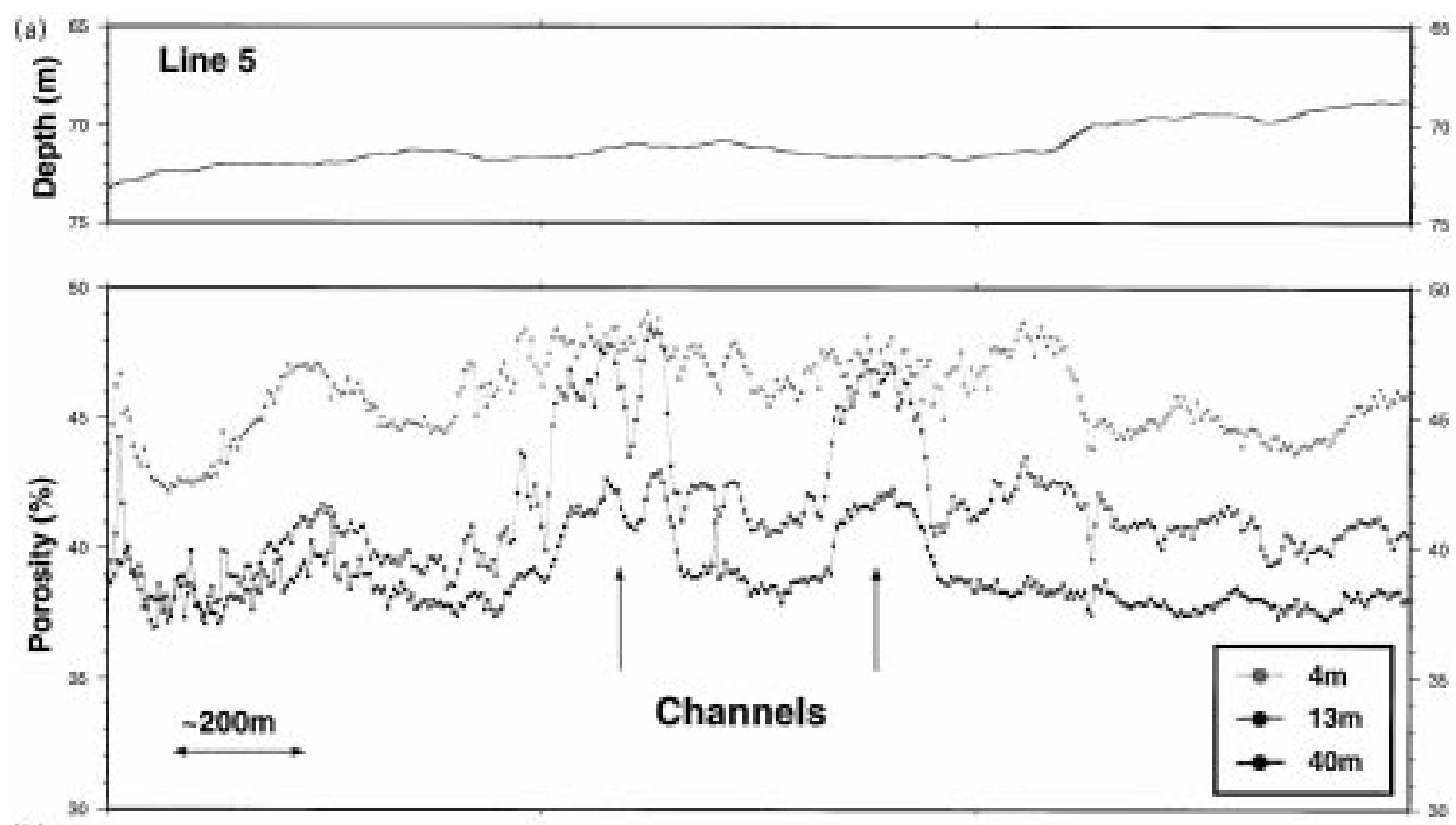

(b)

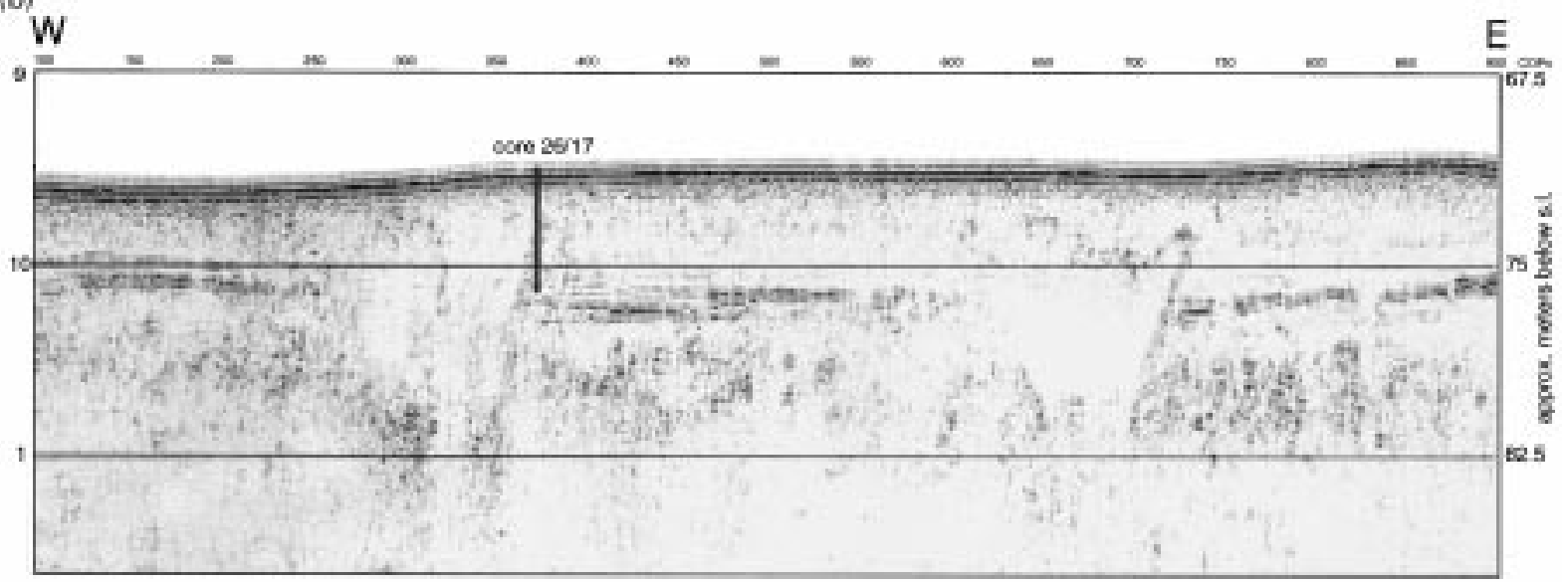

VE 35.1 e $1500 \mathrm{~ms}$

Fig. 3. (a) An example of raw data collected across channel systems within the NSA. The $x$-axis is unlabelled, but represents time: the interval between each point corresponds to the duty cycle of the instrument and is about $30 \mathrm{~s}$. The system is towed at a steady rate of about $1.5 \mathrm{knots}$. The channels are approximately $200 \mathrm{~m}$ in width. (b) Seismic reflection data collected with the high-resolution Huntec system across the same sequence of channels (Davies and Austin, 1997).

electrical resistivity. Archie's law can be written as

$\rho_{\mathrm{m}}=\rho_{\mathrm{f}} \phi^{-m}$

where $\rho_{\mathrm{m}}$ is the measured resistivity, $\rho_{\mathrm{f}}$ is that of seawater and $\phi$ is the porosity. The exponent $m$ is a free parameter, but is typically about $1.4-1.5$ for marine sands and increases as the grains become less spherical (Jackson et al., 1978). While this conversion contains several key assumptions, the approach has been shown to be reliable for data collected off California through comparisons of EM inferred porosities and core profiles (Evans et al., 

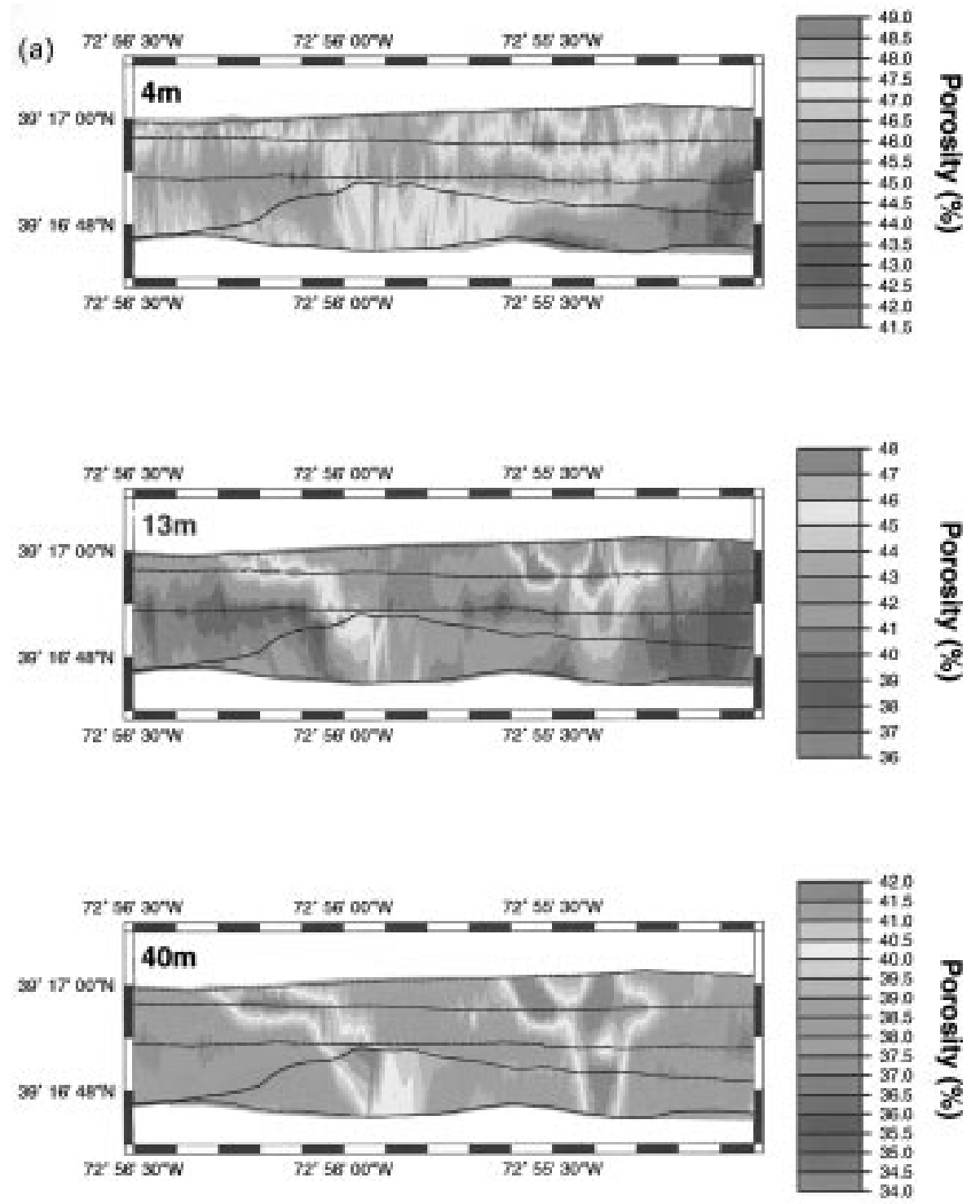

Fig. 4. (a) A contour map of apparent porosities measured on each of the three receivers throughout the NSA. The geometry of the high porosity regions shown on the $40 \mathrm{~m}$ receiver closely resemble that of the depth to the base of channels (b) (Austin et al., 1996; Davies and Austin, 1997). Note that different color scales have been used for each map in (a). (b Reproduced in color in Duncan et al., 2000; Fig. 10b.)

1999), as well as for laboratory measurements on samples (Jackson et al., 1978; Andrews and Bennett, 1984). We have chosen an exponent of 1.8 to calculate apparent porosities, an appropriate value in formations of $50-60 \%$ porosity near the seafloor. At depth or when porosity is around $40 \%$, an exponent of 1.8 will over-predict porosity by $5 \%$, and in this case a value of 1.4 is more appropriate. An exponent of 1.4 was the smallest value observed by Jackson et al. (1978) for marine sands, and so provides a reasonable lower bound on porosity.

We completed a series of lines throughout the two areas that featured previous 3D Huntec coverage (Fig. 1). Our goals were to identify the electrical signature of buried channels and to relate these signatures to the nature of the channel infill, the contacts delineating 


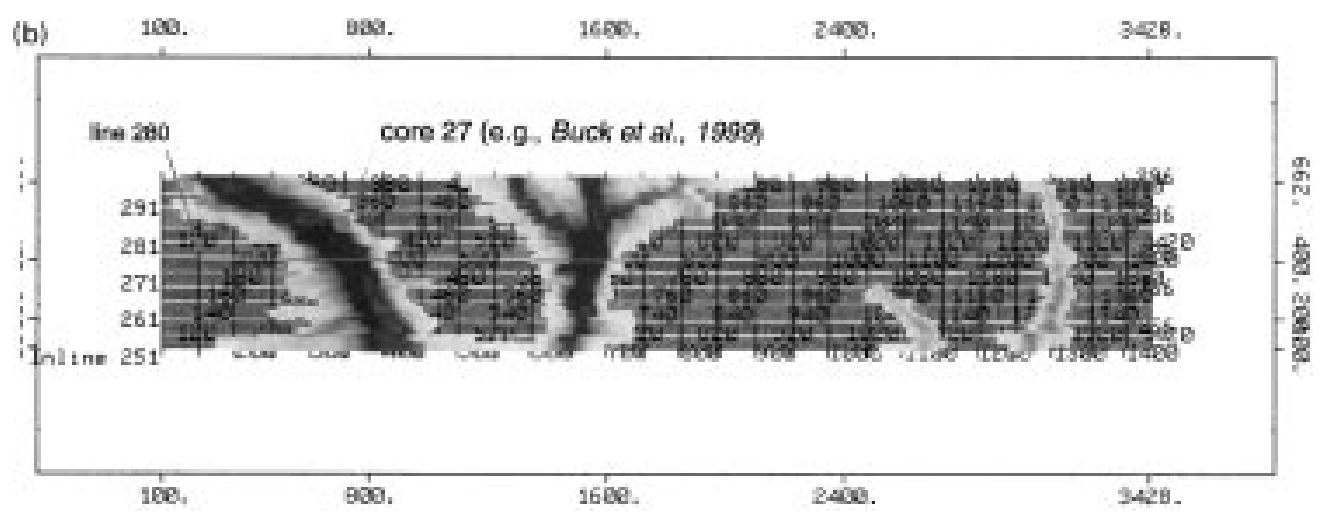

Fig. 4. (continued)

the channel walls and floors, and to place this information in a context that would allow us to understand the conditions under which the channels formed. Below, we will refer to the two survey areas as the northern survey area (NSA) and the southern survey area (SSA). The SSA was the first box surveyed and was reported in Davies et al. (1992). The NSA was described in Austin et al. (1996) and Davies and Austin (1997) and more recently in Buck et al. (1999).

\section{Northern survey area}

According to the map of post-R sediment thickness shown in Milliman et al. (1990), the NSA lies along the inner edge of the outer-shelf wedge, and is covered by generally $2-3 \mathrm{~m}$, and at most $5 \mathrm{~m}$, of post-R sediment (Fig. 2). Water depth in this region is between 70 and $80 \mathrm{~m}$. We completed five east-west lines through the NSA, over an $8 \mathrm{~h}$ period, as well as several lines around the outskirts of the area. We saw clear signatures of buried channels. To first order, the EM signature of a buried channel in this region is marked by increases in the apparent porosities on the 13 and $40 \mathrm{~m}$ receivers within the confines of the channel as previously defined seismically (Fig. 3). These increases are repeatable in subsequent crossings of the channels, so that simple contour maps of the apparent porosities measured by the $13 \mathrm{~m}$, and particularly the $40 \mathrm{~m}$ receiver, reveal the geometry of the buried channels (Fig. 4). These contour maps reveal essentially similar structure in terms of porosity as the "depth to channels reflector" presented in Davies and Austin (1997; Fig. 6).

Numerous other EM channel signatures were seen to the south and south-west of the NSA. Within this region, the channel signatures are generally confined to the 13 and $40 \mathrm{~m}$ receivers. The two sets of channels are characterised by increases in porosity on the $13 \mathrm{~m}$ receiver of up to 6 and $4 \%$ on the $40 \mathrm{~m}$ receiver. The sides of the channels are defined sharply and consistently (Fig. 3).

The increase in apparent porosity within the channel confines can be explained by infilling with high porosity material (similar in porosity to the material within the upper few metres of the seafloor). Knowing the depth to the base of the channel from seismic profiles alleviates some of the ambiguity in interpreting the porosity of the infilling material. The raising of porosity on the $40 \mathrm{~m}$ receiver reveals a reasonable porosity contrast between sub-R sediments and those overlying and infilling the channels. This supports previous interpretations of $\mathbf{R}$ as representing an erosional surface that may have been subaerially exposed and weathered.

We have approximated the response of a $2 \mathrm{D}$ channel structure by computing a series of changing 1D responses, mimicking a traverse across a channel structure. The method is useful as it provides a demonstration of how the measured raw data look across some of the buried structures we are discussing. The modeling consists of two parts: defining a region of normal layered seafloor resistivities which acts as a background reference, and assessing the resistivity structure, also layered, within the channel. These 
(1)

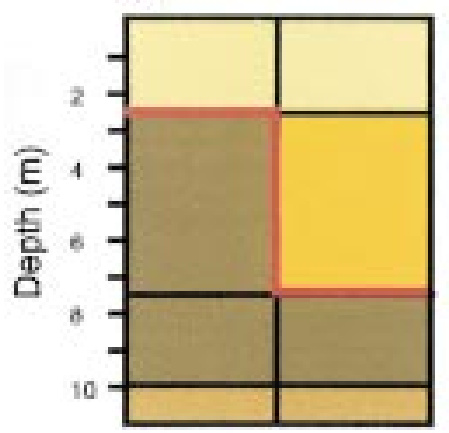

(2)

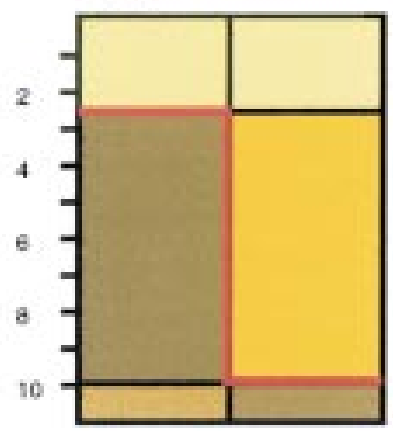

(3)

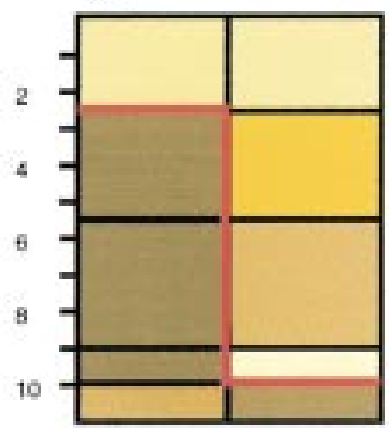

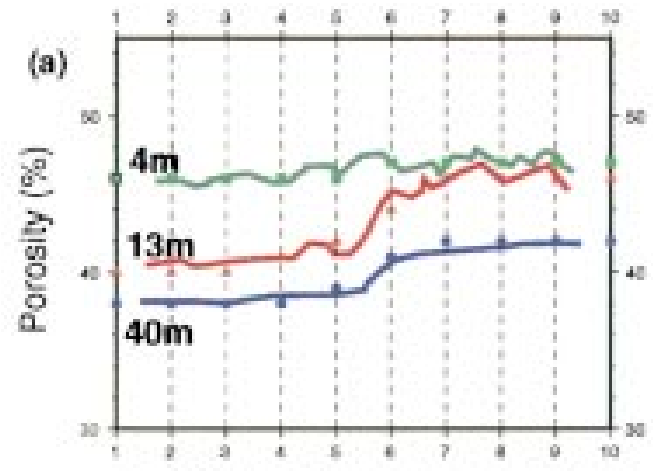

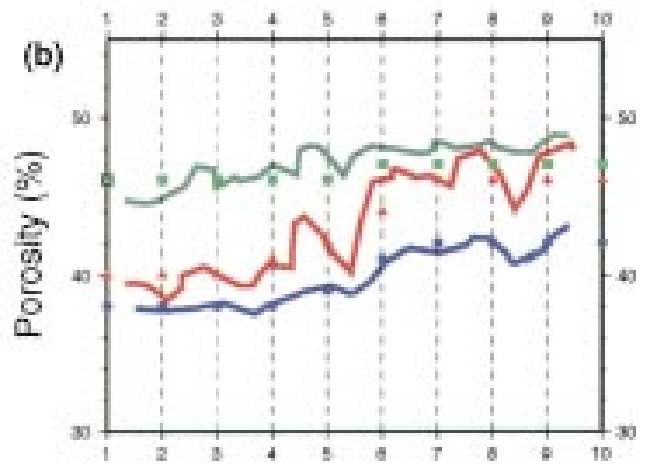

Fig. 5. Pseudo-2D models of channels systems and their synthetic EM responses. These responses and models consider: 1. a channel containing higher porosity material than the surroundings to a depth of about $7.5 \mathrm{~m} ; 2$. a similar porosity structure, but with the channel depth extending to around $10 \mathrm{~m} ; 3$. a $10 \mathrm{~m}$ deep channel with a high porosity band of material at its base, capped by an overlying lower porosity unit above which the porosity increases towards the seafloor. This model would be consistent with the base of the channel containing sandy sequence. The walls of the channel are denoted by the red line in each model. The three models all produce responses that match the data, within the data resolution, although only the response from model 3 is shown against the data in (a) and (b). The model response is shown by the symbols $(4 \mathrm{~m}-$ green squares; $13 \mathrm{~m}$ - red triangles; $40 \mathrm{~m}$ - blue circles). (a) and (b) show crossings of two channels within the NSA, also shown in Fig. 3. 
two layered structures are placed adjacent to each other and a new model, discretized onto a grid with 20 columns, is constructed (Fig. 5). Columns 1-10 are described by the normal resistivity-depth profile and columns 11-20 represent the left-hand half of the channel, which we assume is symmetric. At each depth interval in each column of the model we performed a lateral averaging of $\log$ (resistivity) between columns using a Gaussian weighting function. In column 5, for example, the closest lateral change in resistivity occurs in column 11 , and in this case the weighting function is constructed to return the original column 5 resistivity profile. Closer to the boundary between the two parts of the model, in columns $8-12$, the weighted resistivities represent a lateral average between the two models. After this averaging is performed and new resistivity-depth profiles for each column are obtained, each column is treated as a $1 \mathrm{D}$ resistivity profile and the magnetic field amplitudes and phases that the towed EM system would record above such a 1D layered structure were calculated. This method is not a true 2D response calculation as the horizontal spatial scale is not well determined and is dependent on the Gaussian weighting function, nor is it clear that the process of averaging $\log$ (resistivity) results in accurate responses. However, field data are seen to be well behaved as the system crosses lateral changes in resistivity (i.e. apparent resistivity is continuous) and our numerical approach produces responses that mimic the observed behavior and that are correct at each edge. Appropriate errors, the same as those applied to field data, were applied to these synthetic values. The amplitude and phase values for each receiver were then inverted for an apparent resistivity, and from there to an apparent porosity using our standard field techniques, described above.

We have calculated synthetic responses of a variety of hypothetical channel structures (Fig. 5). We have used the constraints from seismic data that the depth to the base of the channel is in the region of 7.5-10 m below the seafloor as a guide in modeling. The three models shown in Fig. 5 all produce responses that match the data, within the data resolution, although only the response from model 3 is shown against the data.

The responses shown in Fig. 5a and b are clearly an acceptable match to the data (i.e. the RMS misfit between the response and the data is appropriate). However, there are many other structures that could yield the observed responses in addition to those considered. For example, deeper channels, extending to about $20 \mathrm{~m}$ depth and infilled with material of about $40 \%$ porosity would match the data but we rule this possibility out on the basis of the seismic data. The responses shown also demonstrate that the $4 \mathrm{~m}$ receiver only senses structure within the uppermost 2-3 m of seafloor and its response is unaffected by the presence of the channels. Other channel responses, seen on line 9 in the southwestern corner of the NSA, are narrower than those shown in Fig. 3, but the $13 \mathrm{~m}$ receiver shows higher apparent porosities within the confined of the channel than the $4 \mathrm{~m}$ receiver. This observation supports a model, such as model 3 in Fig. 5, with higher porosity units than the surroundings forming at least part of the channel fill material.

The outer-shelf extension of line 9 (not shown), crossing the outer-shelf sediment wedge to a water depth of $85 \mathrm{~m}$, shows similar porosities on the 4 and $13 \mathrm{~m}$ receivers beginning at a water depth of about $70 \mathrm{~m}$, indicating a uniform uppermost sequence of sediment extending to a depth of at least $7 \mathrm{~m}$. Within this portion of the line, another channel is seen, most likely the southerly extension of the easternmost system within the NSA. This channel system differs from that to the north inasmuch as the $4 \mathrm{~m}$ receiver also shows an increase in porosity, indicating the presence of higher porosity material within about $1 \mathrm{~m}$ of the seafloor. The regions surrounding the channel are consistent with a wedge of sediment about $10 \mathrm{~m}$ thick. This model is consistent with the findings of Milliman et al. (1990), which predicts that line 9 begins off the western edge of the outer-shelf wedge and continues across it.

\section{Southern portion of the outer-shelf wedge}

The SSA is described by an area in the southwestern region of the outer-shelf wedge, the westernmost boundary of which lies just off the wedge itself in a region where $\mathbf{R}$ outcrops on the seafloor (Davies et al., 1992). Water depth here is around $70 \mathrm{~m}$.

At the western end of the SSA, the background porosity structures are in the range of $40-43 \%$ on 

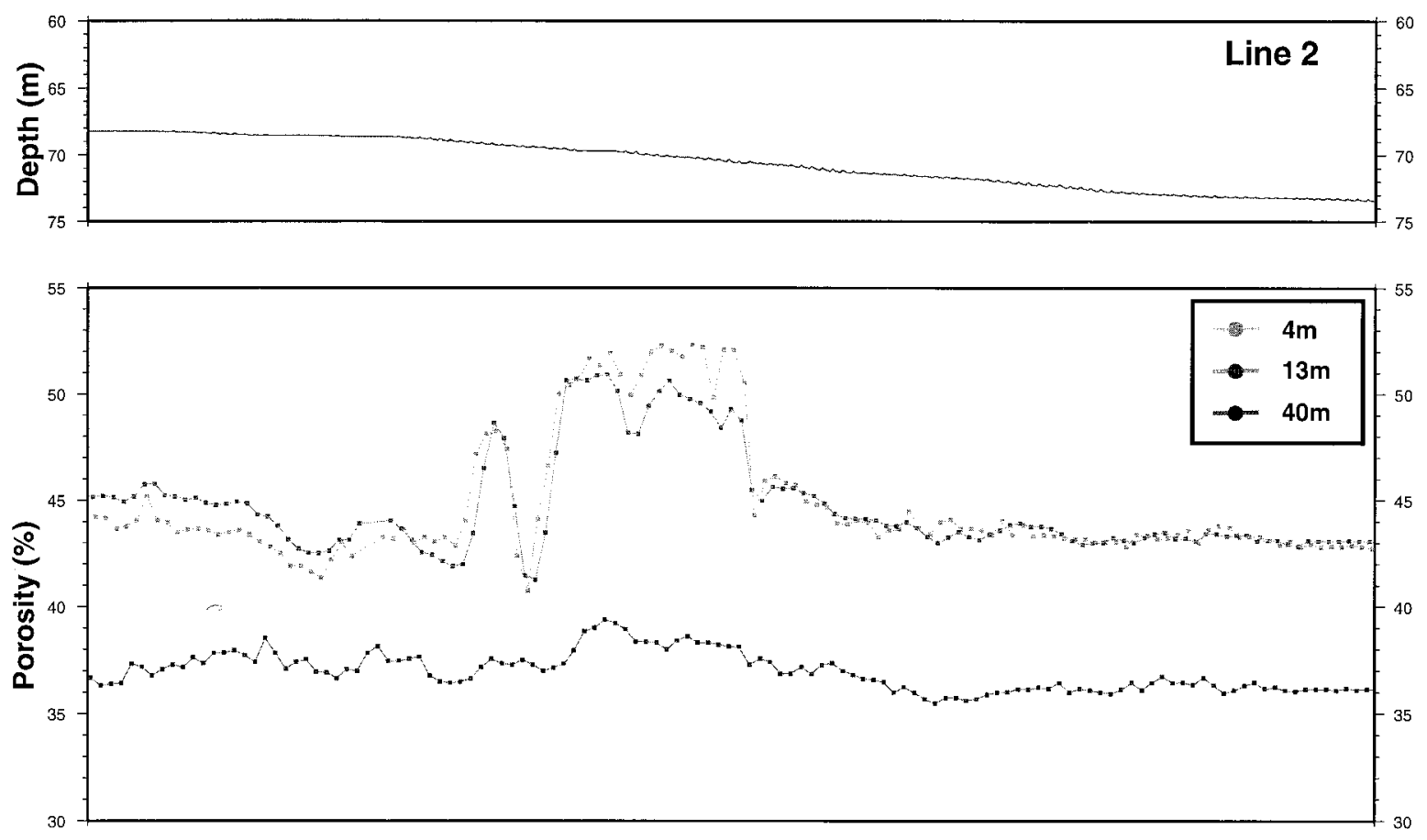

Fig. 6. Data collected across a shallow channel system at the western end of the SSA. Note that in contrast to channels in the NSA, there is no significant change in apparent porosity on the $40 \mathrm{~m}$ receiver, indicating that channels are shallower in this region. The outline of the seismically determined channel is superimposed.

the $4 \mathrm{~m}$ receiver. In contrast to the northern region, the channels here have a signature on the $4 \mathrm{~m}$ receiver denoted by an increase of about 3-5\% in apparent porosity. There is also an increase in porosity of about $4-5 \%$ on the $13 \mathrm{~m}$ receiver above the background of $38-43 \%$ porosity (Fig. 6). Little or no signal of the channel is seen on the $40 \mathrm{~m}$ receiver. This would suggest that the channels at the western end of the SSA are closer to the seafloor than in the NSA. Indeed, seismic reflection data show that $\mathbf{R}$ at this western edge of the outer-shelf wedge is overlain by at most a veneer of sandy material and the depth to the base of the channels here is around 4-5 $\mathrm{m}$ rather than the $7-10 \mathrm{~m}$ within the NSA. This response is consistent with a channel filled with high porosity material (53-55\%) carved to a depth of about 3.5$4 \mathrm{~m}$ in a material with a surficial porosity of about $45 \%$ underlain by a lower porosity (30\% unit) about $7 \mathrm{~m}$ beneath the seafloor.

At the eastern end of the SSA, a prominent channel system was reported by Davies et al. (1992). This feature, which is at a similar depth below the seafloor as the channels in the NSA, was delineated by seismic reflector channels that overlies $\mathbf{R}$ towards the outershelf, and which is truncated further west as $\mathbf{R}$ shoals towards the seafloor. The nature of channels is weaker than $\mathbf{R}$ between channel signatures, and it is irregular in nature. Even within the confines of incisions, the amplitude of reflected energy seems to be less from the channels reflector than from $\mathbf{R}$. The channels mapped out by Davies et al. (1992) form a meandering system draining towards the south-southeast. We completed a number of lines across this region with sufficient density to map out the same channel geometry as seen by Davies et al. (1992). On repeated crossings of the channel reflector, there was no recognizable response from the EM system (Fig. 7). Instead, the data show a band of lower porosity material on the $4 \mathrm{~m}$ receiver (40-42\%) that trends roughly northeast when data from all crossings are merged to form a contoured porosity map (Fig. 8). There is some trace of this band of material on the $13 \mathrm{~m}$ receiver, 

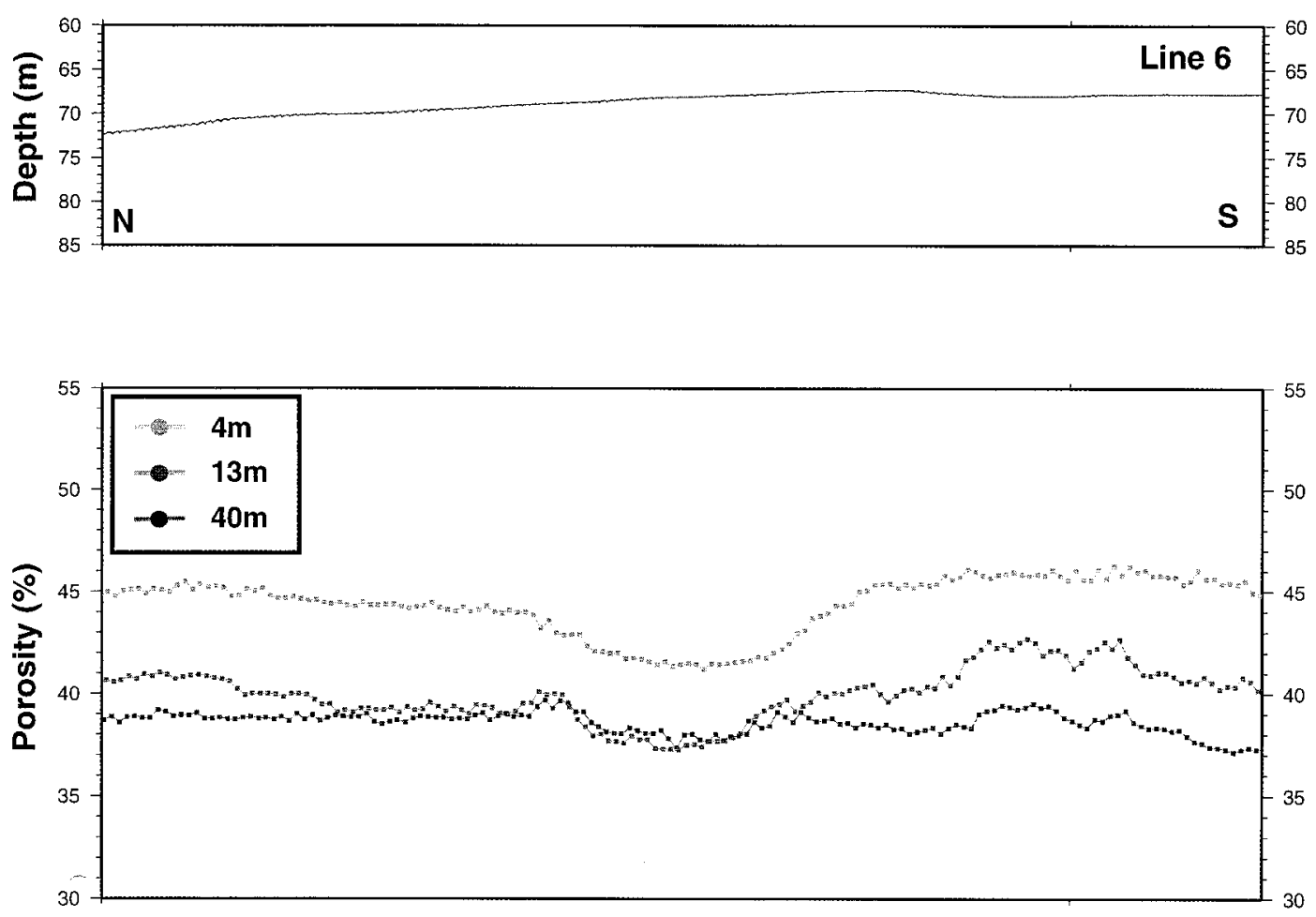

Fig. 7. An example of the raw data collected across the eastern portion of the SSA, showing the absence of a channel signature. The decrease in porosity on the 4 and $13 \mathrm{~m}$ receivers is in the same location as the seismically observed channel, but has different spatial characteristics.

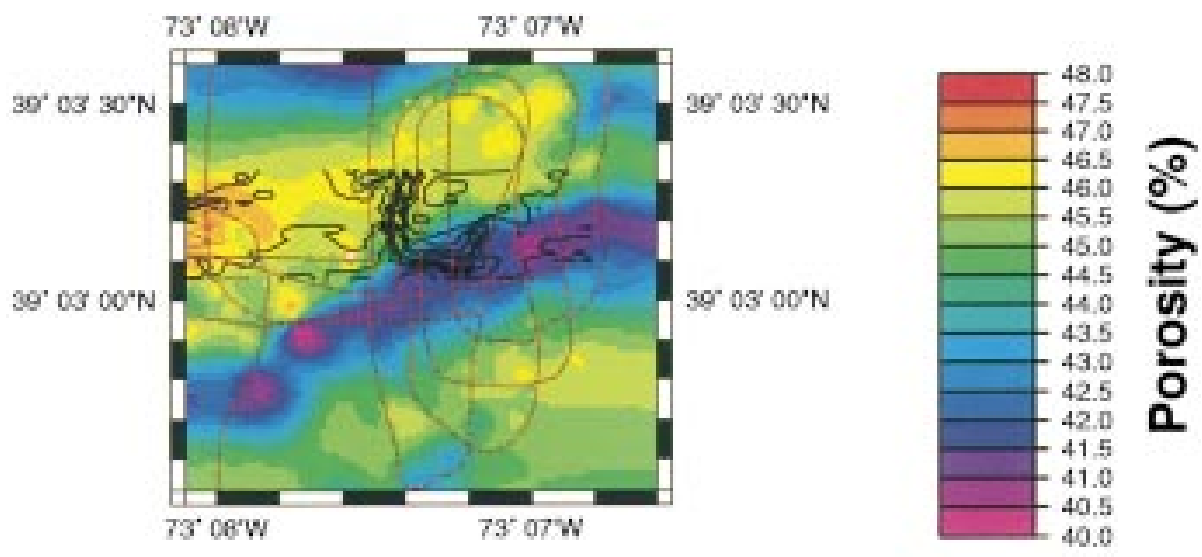

\section{4m Receiver}

Fig. 8. A contour map of the region within the SSA where Davies et al. (1992) showed a channel system. Instead of the channels, the EM system records a NE trending band of low porosity material, presumably associated with deposition and reworking of the outer-shelf sediment wedge. 
while the $40 \mathrm{~m}$ receiver shows patchy variations of a few percent apparent porosity around a mean of about $39 \%$. This band of material approximately follows the contours of the sediment wedge thicknesses and so may constitute a distinct band of material laid down at the later stages of the wedge formation. There is no recognizable pattern in the apparent porosities of any of the receivers that corresponds to the channel structure presented in Davies et al. (1992).

\section{Discussion}

The EM system responds to several influences in the seafloor. These include changes in bulk porosity caused by a change in grain size, and changes in the degree of compaction or diagenesis. These are all bulk changes in physical properties. On the other hand, seismic reflection profiling can be influenced by a broader range of local features: while large scale changes in bulk properties can act as a reflector of seismic energy, so too can smaller, more localized changes. While strong amplitude reflections will occur across major lithologic boundaries, reflections can also occur across less dramatic boundaries, or from interbedding of many thin sand and mud layers with minor impedance contrasts across each layer (e.g. Esker et al., 1996).

Our survey found two distinct EM responses associated with postulated buried channels that were imaged seismically: one that was easily identified with those channels and another that failed to respond to a seismically observed channel at all. One important link between the channels that do have a clear and recognizable electrical signature is that they are all seen to incise the seismic reflector $\mathbf{R}$. The channel set at the eastern end of the SSA, which does not have an electrical signature, sits above the $\mathbf{R}$ reflector and does not cut it.

The EM responses of the northern channels are consistent with structures about 7-10 m deep with a high porosity unit a few meters thick lining their bases, possibly sands that have not yet compacted. In general, clear EM channel signatures are seen where Milliman et al. (1990) show a minimal to zero thickness of late Quaternary sediment. While this is a necessary condition to see channels, it is not sufficient; no channel signatures were seen along about $80 \%$ of line 3 (Fig. 1), which was run roughly parallel to the shelf break beginning to the southwest of the NSA, indicating that such structures are not ubiquitous but are rather confined to specific locations on the shelf. Duncan et al. (2000) show widespread channel signatures around the NSA as well as to the south and east of the NSA, although not to the southwest.

The channel set within the SSA which shows up so clearly in reflection profiling but not in EM imaging must not have a substantial change in bulk properties between the channel infill and the channel base and walls. There may be a thin weathering surface that acts as a sufficient reflector of seismic energy, but which is too thin to have an impact on the EM data. While the EM data indicate a gradient of porosity with depth, this is a normal signature of marine sediments reflecting depth dependent compaction. Thus, there is not necessarily a change in material deposited before and after formation of the channel. If these channels were cut over an extended period of time in a subaerial environment, then we would expect that weathering of the wall and floor material would raise its resistivity above that of any infill material. While this scenario is compatible with the channels that incise $\mathbf{R}$, it is not compatible with those carved in the mid-shelf wedge. This would suggest that these channel sets formed during a fairly brief hiatus, and possibly in a nearshore environment, followed by deposition of the overlying unit.

There are several scenarios in which the various channels could have been carved. These scenarios are dependent on the formation dates of $\mathbf{R}$ and the source of sediment for the outer-shelf wedge, both of which are disputed. Our data by themselves are not sufficient to discriminate between the two models, which will require detailed drilling to determine dates for each lithostratigraphic unit. The standard concept is that the channels were subaerially carved as sealevel rose, and the shoreline retreated towards its present position (Buck et al., 1999). In this model, the channels were subaerially carved both into $\mathbf{R}$ and the outer-shelf wedge at the same time (around $18.5-22 \mathrm{ka}$ ), with $\mathbf{R}$ having been formed earlier. After this, sealevel rose steadily and fresh deposits covered and filled the channels (Duncan et al., 2000). The other model considers $\mathbf{R}$ to have been carved during the maximum lowstand (18.5-22 ka). R-incising 
channels could have been formed while the surface was subaerially exposed. Input for the lower portions of the outer-shelf wedge have been proposed to derive from the catastrophic drainage of glacial lakes (Uchupi et al., 2000). Evidence for this includes the lobate shapes of deposits seen across the shelf the chronology of de-glaciation and the presence of large glacial lakes across much of modern New England and the observations of large boulders and Mammoth bones on the shelf. The first deposition would have occurred between 16 and $18 \mathrm{ka}$ and would have been subaerial. The second event would have been around 10-13 ka and, in the outer-shelf region, would have been in a nearshore environment. It is possible that the channels above $\mathbf{R}$, carved in the lower portion of the outer-shelf wedge, could have been cut as outflow channels in a nearshore environment as part of the rapid and energetic deposition event.

\section{Conclusions}

A towed EM survey has mapped the near surface porosity structure of a portion of the New Jersey continental shelf. Our survey found two distinct EM responses associated with postulated buried channels that were imaged seismically: one that was easily identified with those channels and another that failed to respond to the seismically observed channel at all. One important link between the channels that do have a clear and recognizable electrical signature is that they are all seen to incise the regional seismic reflector $\mathbf{R}$. The channel set at the eastern end of the SSA which does not have an electrical signature is carved above $\mathbf{R}$.

The patterns of porosity seen within the two channel sets suggest that those carved above reflector $\mathbf{R}$ were associated with rapid deposition with only a brief hiatus during which the channels were carved. Were these channels to have been cut subaerially over an extended period of time, then we would have expected to see a measurable change in physical properties across their boundaries. While our data cannot definitively discriminate between the two competing hypotheses for shelf sedimentation since the Wisconsinan deglaciation, we prefer a model in which the outer-shelf wedge and the channels carved into it occurred through the catastrophic breaching of glacial lakes (Uchupi et al., 2000).

The tight constraints placed on the walls of the channels by seismic reflection allow a much better interpretation to be made of the physical properties within the channel from EM data. This fact demonstrates further the power of combining complementary geophysical techniques to understand geological structure. The EM data presented were relatively quick and cheap to acquire, making this an attractive additional tool for surveying the continental shelf.

\section{Acknowledgements}

Data acquisition was completed during $R / V$ Oceanus voyage 329 with John Collins as the chief scientist. We would like to thank the captain and crew of the Oceanus for their help. Also, Matt Gould and Rob Handy along with other members of John Collin's seismic group assisted in our deck operations and are thanked. Bathymetry and sidescan data were kindly provided by John Goff (UTIG). Jamie Austin (UTIG) is thanked for providing coordinates of the two Huntec survey areas. Thoughtful reviews by Jamie Austin and Graham Heinson considerably improved the paper. Neal Driscoll and Elazar Uchupi provided helpful input on the issue of channel formation. Laurie Schuur Duncan kindly provided the seismic images for Figs. 3 and 4. Many of the other figures were produced with the GMT software package (Wessel and Smith, 1995). Funding for this project was provided by the Office of Naval Research grant N00014-98-1-0506 through the office of Dr J. Kravitz, whose support is much appreciated.

\section{References}

Andrews, D., Bennett, A., 1984. Measurements of diffusivity near the sediment-water interface with a fine scale resistivity probe. Geochim. Cosmochim. Acta 45, 2169-2175.

Archie, G.E., 1942. The electrical resistivity log as an aid in determining some reservoir characteristics. J. Pet. Technol. 5, 1-8.

Austin, J.A., Fulthorpe, C.S., Mountain, G.S., Orange, D.L., Field, M.E., 1996. Continental-margin seismic stratigraphy: assessing the preservation potential of heterogeneous geologic processes operating on continental shelves and slopes. Oceanography 9, 173-177.

Buck, K.F., Olsen, H.C., Austin Jr., J.A., 1999. Paleoenvironmental evidence for latest Pleistocene seal-level fluctuations on the 
New Jersey outer continental shelf: combining high resolution sequence stratigraphy and foraminiferal analysis. Mar. Geol. 154, 287-304.

Cheesman, S.J., Law, L.K., St. Louis, B., 1993. A porosity survey in Hecate Strait using a seafloor electro-magnetic profiling system. Mar. Geol. 110, 245-256.

Davies, T.A., Austin Jr., J.A., Lagoe, M.B., Milliman, J.D., 1992. Late Quaternary sedimentation of New Jersey: new results using 3D seismic profiles and cores. Mar. Geol. 108, 323-343.

Davies, T.A., Austin Jr., J.A., 1997. High-resolution 3D seismic reflection and coring techniques applied to late Quaternary deposits on the New Jersey shelf. Mar. Geol. 143, 137-149.

Duncan, C.S., Goff, J.A., Austin, J.A., Fulthorpe, C.S., 2000. Tracking the last sea-level cycle: seafloor morphology and shallow stratigraphy of the latest Quaternary New Jersey middle continental shelf. Mar. Geol. 170, 395-417.

Emery, K.O., Uchupi, E., 1984. The geology of the Atlantic Ocean. Springer, New York (1050pp.).

Evans, R.L., Law, L.K., St. Louis, B., Cheesman, S., Sananikone, K., 1999. The shallow porosity structure of the continental shelf of the Eel Shelf, Northern California: results of a towed electromagnetic survey. Mar. Geol. 154, 211-226.

Esker, D., Sheridan, R.E., Ashley, G.M., Waldner, J.S., Hall, J.S., 1996. Synthetic seismograms from vibracores: a case study in correlating the late quaternary seismic stratigraphy of the New Jersey inner continental shelf. J. Sed. Res. 66, 1156-1168.

Goff, J.A., Swift, D.J.P., Duncan, C.S., Mayer, L.A., Hughes-
Clarke, J., 1999. High resolution swath sonar investigation of sand ridge, dune and ribbon morphology in the offshore environment of the New Jersey margin. Mar. Geol. 161, 307-337.

Knebel, H.J., Spiker, E.C., 1977. Thickness and age of surficial sand sheet, Baltimore Canyon Trough area. Am. Assoc. Pet. Geol. Bull. 61, 861-871.

Jackson, P.D., Taylor-Smith, D., Stanford, P.N., 1978. Resistivityporosity-particle shape relationships for marine sands. Geophysics 43, 1250-1268.

Lagoe, M.B., Davies, T.A., Austin, J.A., Olsen, H.C., 1997. Foraminiferal constraints on very high-resolution seismic stratigraphy and late quaternary history, New Jersey continental shelf. Palaois 12, 249-266.

Mayer, L.A, Hughes-Clarke, J.E, Goff, J.A, Schuur, C.L, Swift, D.J.P, 1996. Multibeam sonar bathymetry and imagery from the New Jersey continental margin; preliminary results. EOS Trans. AGU 77, 329.

Milliman, J.D., Jiezao, Z., Anchun, L., Ewing, J.I., 1990. Late Quaternary sedimentation on the outer and middle New Jersey continental shelf: result of two local deglaciations. J. Geol. 98, 966-976.

Uchupi, E., Driscoll, N., Ballard, R.D., Bolmer, S.T., 2000. Drainage of Late Wisconsin glacial lakes and the morphology and late Quaternary stratigraphy of the New Jersey-Southern New England continental shelf and slope, submitted for publication.

Wessel, P., Smith, W.H.F., 1995. New version of generic mapping tools released. Eos. Trans. Am. Geophys. Union 76, 329. 